\title{
Level of neutral buoyancy, deep convective outflow, and convective core: new perspectives based on 5 years of CloudSat data
}

Article

Published Version

Takahashi, H., Luo, Z. J. and Stephens, G. L. (2017) Level of neutral buoyancy, deep convective outflow, and convective core: new perspectives based on 5 years of CloudSat data. Journal of Geophysical Research: Atmospheres, 122 (5). pp. 2958-2969. ISSN 2169-8996 doi: https://doi.org/10.1002/2016JD025969 Available at https://centaur.reading.ac.uk/71391/

It is advisable to refer to the publisher's version if you intend to cite from the work. See Guidance on citing.

To link to this article DOI: http://dx.doi.org/10.1002/2016JD025969

Publisher: American Geophysical Union

All outputs in CentAUR are protected by Intellectual Property Rights law, including copyright law. Copyright and IPR is retained by the creators or other copyright holders. Terms and conditions for use of this material are defined in the End User Agreement. 


\section{www.reading.ac.uk/centaur}

\section{CentAUR}

Central Archive at the University of Reading

Reading's research outputs online 


\section{Journal of Geophysical Research: Atmospheres}

\section{RESEARCH ARTICLE \\ 10.1002/2016JD025969 \\ Key Points: \\ Level of neutral buoyancy, deep convective outflow, and convective core: New perspectives based on 5 years of CloudSat data}

- The difference between

LNB_sounding and LNB_observation

can be interpreted as a measure of entrainment dilution

- Deep convection over the Warm Pool experiences larger entrainment dilution than that over the two tropical land regions

- The deep convective outflow height is probably linked to moisture supply and convective life cycle

Correspondence to:

H. Takahashi and Z. J. Luo,

Hanii.Takahashi@jpl.nasa.gov;

zluo@ccny.cuny.edu

\section{Citation:}

Takahashi, H., Z. J. Luo, and

G. L. Stephens (2017), Level of neutral

buoyancy, deep convective outflow,

and convective core: New perspectives

based on 5 years of CloudSat data,

J. Geophys. Res. Atmos., 122, 2958-2969,

doi:10.1002/2016JD025969.

Received 26 SEP 2016

Accepted 20 FEB 2017

Accepted article online 22 FEB 2017

Published online 8 MAR 2017

\author{
Hanii Takahashi ${ }^{1,2}$ (D) Zhengzhao Johnny Luo ${ }^{3}$ (D), and Graeme L. Stephens ${ }^{1,4}$ (D) \\ ${ }^{1}$ Joint Institute for Regional Earth System Science and Engineering, University of California, Los Angeles, California, USA, ${ }^{2}$ Jet \\ Propulsion Laboratory, California Institute of Technology, Pasadena, California, USA, ${ }^{3}$ Department of Earth and Atmospheric \\ Sciences and NOAA-CREST Institute, City University of New York, City College, New York, New York, USA, ${ }^{4}$ Department of \\ Meteorology, University of Reading, Reading, UK
}

Abstract This paper is the follow on to a previous publication by the authors, which investigated the relationship between the level of neutral buoyancy (LNB) determined from the ambient sounding and the actual outflow levels using mainly CloudSat observations. The goal of the current study is to provide a more complete characterization of LNB, deep convective outflow, and convective core, and the relationship among them, as well as the dependence on environmental parameters and convective system size. A proxy is introduced to estimate convective entrainment, namely, the difference between the LNB (based on the ambient sounding) and the actual outflow height. The principal findings are as follows: (1) Deep convection over the Warm Pool has larger entrainment rates and smaller convective cores than the counterpart over the two tropical land regions (Africa and Amazonia), lending observational support to a long-standing assumption in convection models concerning the negative relationship between the two parameters. (2) The differences in internal vertical structure of convection between the two tropical land regions and the Warm Pool suggest that deep convection over the two tropical land regions contains more intense cores. (3) Deep convective outflow occurs at a higher level when the midtroposphere is more humid and the convective system size is smaller. The convective system size dependence is postulated to be related to convective lifecycle, highlighting the importance of cloud life stage information in interpretation of snapshot measurements by satellite. Finally, implications of the study to global modeling are discussed.

\section{Introduction}

Deep convection is a key mechanism by which near-surface air is transported to the upper troposphere and lower stratosphere (UT/LS) in a relatively short timeframe. As such, it affects the UT/LS heat budget and trace gas distribution (e.g., water vapor and ozone) in profound ways [Sherwood et al., 2003; Kuang and Bretherton, 2004, Danielsen, 1982, Kley et al., 2007; Luo et al., 2012, among others]. The vertical convective transport, which is usually confined to the narrow convective cores, will eventually transition to horizontal outflows in the upper troposphere, extending the influence of deep convection to a much larger area through development of widespread cirrus anvils that last significantly longer than the original convection. Cirrus spawned out from deep convection also plays a significant role in radiative heating of the atmosphere, which, in turn, affects the large-scale circulation and organization of convective systems through various forms of radiativeconvective feedbacks [e.g., Stephens et al., 2008].

An important aspect of the deep convection-to-outflow transition is the altitude (or the range of altitudes) at which the outflow occurs. Theoretical studies have related deep convective outflow to the environment in which convection develops. From an energy balance consideration, Hartmann and Larson [2002] argued that tropical mean deep convective detrainment is largely controlled by the clear-sky longwave cooling profiles. At smaller scales, the deep convective outflow is traditionally determined by the ambient temperature and moisture profile, which can be conveniently summarized in a single parameter called the level of neutral buoyancy (LNB) or the equilibrium level (EL) [Wallace and Hobbs, 2006]. The LNB can be computed from the parcel theory by lifting a near-surface air parcel adiabatically to the upper troposphere where the air parcel starts to lose buoyancy.

A few observational studies have been undertaken to understand the relationship between deep convective outflow and LNB. Mullendore et al. [2009] used a case study from the Tropical Rainfall Measuring Mission 
(TRMM) Large-Scale Biosphere-Atmosphere field campaign to show that the level of maximum detrainment of an observed convective system is significantly lower than the LNB derived from the ambient sounding profiles. A previous study by the authors [Takahashi and Luo, 2012, hereinafter referred to as TL12] generalized the conclusion for the whole tropics by analyzing 2.5 years of CloudSat observations, which include thousands of deep convective systems. TL12 found that the height difference between the LNB derived from the ambient sounding profiles and the actual outflow level varies significantly from land to ocean (smaller over land than ocean) and that this difference is related to the underlying convective processes such as entrainment rates. Entrainment dilutes convective motion and dampens convective buoyancy and makes convective air parcels lose buoyancy at a lower altitude, thus lower outflow level. One objective of this present study is to build upon the initial work by TL12 and develop a deeper and more comprehensive understanding of the relationship between LNB and deep convective outflow including regional variations.

Convective outflow and entrainment rate are connected to the macrophysical and microphysical characteristics of convective cores, a subject that is also investigated in this study. A deep convective core is a relatively well-protected area inside the convective system that has large vertical velocity on the order of $10 \mathrm{~m} / \mathrm{s}$. Strong deep convective cores occasionally overshoot the corresponding LNB because of inertia. The overshooting turrets may mix irreversibly with the UT/LS environment affecting the UT/LS heat and composition [e.g., Luo et al., 2008; Iwasaki et al., 2012]. In the past, overshooting convection was studied most often using satellite-borne infrared (IR) sensors [e.g., Gettelman et al., 2002; Rossow and Pearl, 2007]. Later, TRMM precipitation radar (PR) was used to characterize the vertical structure of the overshooting cores [Liu and Zipser, 2005]. However, different views emerged concerning the global distribution of overshooting convection. For example, IR sees overshooting convection occurring most frequently over the tropical west Pacific region, whereas TRMM finds them predominantly over land. Liu et al. [2007] reconciled the difference by noting that IR instruments and PR are sensitive to different parts of the convective system. More recently, CloudSat data were employed to shed further light upon the overshooting deep convection [Chung et al., 2008; Luo et al., 2008; Iwasaki et al., 2010, 2012, 2015]. In comparison with TRMM PR which operates at $13.8 \mathrm{GHz}$ with sensitivity at $\sim 17 \mathrm{dBZ}$ and is sensitive mostly to moderate and heavy precipitation, CloudSat carries a $94 \mathrm{GHz}$ cloud profiling radar (CPR; $94 \mathrm{GHz}$ ) with sensitivity at $\sim 30 \mathrm{dBZ}$. The CPR is sensitive to both cloud size and precipitation size particles, which ensures a more complete sampling of the overshooting convection. It is therefore of interest to use CloudSat to study deep convective cores, including the overshooting ones. In particular, we seek to connect findings about LNB, convective outflow, and entrainment rates to the characteristics of deep convective cores.

After a short description of data and methodology (section 2), we first examine the relationship between LNB and deep convective outflow (section 3). Focus is placed on revealing the regional variations of the relationship and exploring how these variations can inform us about the underlying convective processes. The internal vertical structure of deep convective cores and overshooting cores is also studied. A specific question we investigate is the following: how is the internal vertical structure of convective cores related to convective entrainment? Section 4 examines the dependence of deep convective outflow on midtropospheric relative humidity and convective system size. Finally, section 5 summarizes and concludes the study.

\section{Data and Methodology}

Five years (2006-2011) of CloudSat data are analyzed in this study. CloudSat is a Sun-synchronous, polarorbiting satellite, carrying a $94 \mathrm{GHz}$ cloud profiling radar (CPR) that is sensitive to both cloud size and precipitation size particles. The footprint of CloudSat is around $1.7 \mathrm{~km}$ along track and $1.3 \mathrm{~km}$ across track, and the vertical resolution is $480 \mathrm{~m}$ (oversampled to $240 \mathrm{~m}$ ). The equator crossing time of CloudSat is approximately 1:30 A.M. and 1:30 P.M. at local time. Two CloudSat products were used in this study: 2B-GEOPROF data which include both radar reflectivity and cloud mask and ECMWF-AUX data containing temperature and moisture profiles from the European Centre for Medium-Range Weather Forecast (ECMWF) operational analysis interpolated in space and time to the CloudSat track. An overview of the CloudSat mission is provided by Stephens et al. [2008]. Detailed information on CloudSat data can be found from the CloudSat Data Processing Center at http://cloudsat.cira.colostate.edu.

As in TL12, our analysis is based on anvil cloud objects selected from the 2B-GEOPROF product. The selection procedure is as follows. First, we define cloud objects in 2B-GEOPROF data as continuous areas enclosed by 


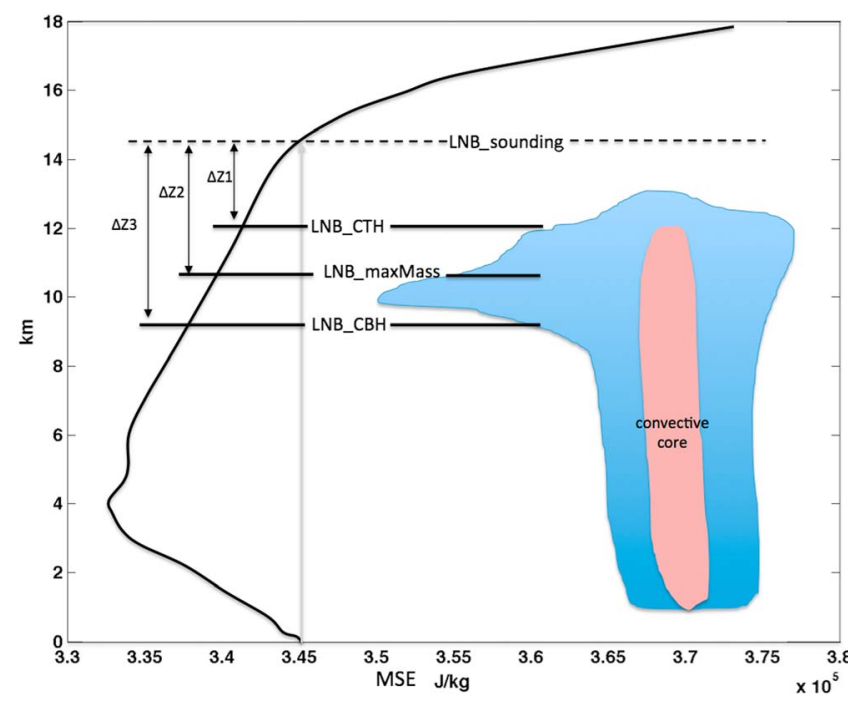

Figure 1. A schematic showing the highest detrainment level (LNB_CTH), the lowest detrainment level (LNB_CBH), and the level where maximum mass detrainment occurs (LNB_maxMass). These quantities were calculated over only the fresh anvil (the first $20 \mathrm{~km}$ of the anvil). The LNB sounding is calculated based on the parcel theory assuming pseudoadiabatic ascent, which corresponds to the level where moist static energy (MSE) is equal to the surface MSE. MSE $=C_{p}+g z+L_{v} q\left(T, z_{i}\right.$ and $q$ are temperature, height, and specific humidity, respectively; $C_{p}$ is the specific heat of condensation). $\Delta Z 1, \Delta Z 2$, and $\Delta Z 3$ are the distances between LNB_sounding and LNB_CTH, LNB_sounding and LNB_maxMass, and LNB_sounding and LNB_CBH, respectively. cloud mask value $\geq 20$, similar to Riley and Mapes [2009] and Bacmeister and Stephens [2011]. Each cloud object so defined represents a vertical cross section of the three-dimensional cloud. Second, we search inside each cloud object for the presence of deep convective core (DCC), defined as a CPR profile having (1) continuous radar echo from cloud top $(\geq 10 \mathrm{~km})$ to within $2 \mathrm{~km}$ of the surface (i.e., we ensure that the target cloud object is rooted in the planetary boundary layer and reaches up to the upper troposphere) and (2) echo top height of $10 \mathrm{dBZ}$ greater than $10 \mathrm{~km}$. Requiring a large radar echo extending into the upper troposphere is meant to be in line with previous works that study the characteristics of deep convective cores [Luo et al., 2008, 2010]. Third, once a DCC is identified, we search on both sides of the cloud object for attached anvils. Cloud base $\geq 5 \mathrm{~km}$ is required for defining anvils, following the statistics of the anvil base height by Yuan and Houze [2010]. We further require that the horizontal extension of the cirrus anvil be greater

than $20 \mathrm{~km}$ to insure that the anvil is well developed and that enough information is available for deriving parameters related to convective outflow. A total of 7320 anvil cloud objects are selected through this procedure based on 5 years of CloudSat 2B-GEOPROF data.

For each selected anvil cloud object, we defined three metrics to characterize the actual outflow level of deep convection, as schematically illustrated in Figure 1: (1) LNB_CTH is defined as the cloud top height (CTH) of the anvil and represents the highest detrainment level, (2) LNB_CBH is defined as the cloud base height $(\mathrm{CBH})$ of the anvil and represents the lowest detrainment level, and (3) LNB_maxMass is the height of the maximum radar reflectivity within the anvil column, which, according to a study of ground-based Doppler radar measurements by Mullendore et al. [2009], corresponds well to the maximum mass detrainment level. Collectively, we refer to the three forms of deep convective outflow as LNB_observation. They are calculated profile by profile first and then averaged over the first $20 \mathrm{~km}$ of the anvils (on both sides). Choice of the first $20 \mathrm{~km}$ of the anvil is a compromise between the need to minimize random noise and the concern of the bias due to ice sedimentation, as described in TL12. LNB_CTH based on CloudSat may be an underestimate of the topmost outflow height since much of the ice cloud above $12 \mathrm{~km}$ is only observed by CALIPSO [e.g., Deng et al., 2015]. However, the difference between CloudSat and CALIPSO is most pronounced in thin cirrus. For convective core and fresh anvils, the radar-lidar difference in cloud top identification becomes diminishingly small [e.g., Wang et al., 2014].

LNB_sounding is estimated from the ambient temperature and moisture sounding profiles, which in this study are obtained from the collocated ECMWF operational analyses (ECMWF-AUX product), assuming pseudoadiabatic ascent from the planetary boundary layer. As explained in TL12, analyses tend to smooth out meteorological fields, so one may expect some underestimation of LNB_sounding. The exact impact is difficult to assess due to lack of collocated radiosonde data. Pseudoadiabatic ascent neglects the effects of hydrometeor loading and freezing. But given that the two effects tend to cancel each other, their impact on LNB_sounding should be small. Emanuel [1994] found a nearly exact cancelation between the two. LNB_sounding is also schematically illustrated in Figure 1, together with three forms of LNB_observation. 
(a) Total Observed Number

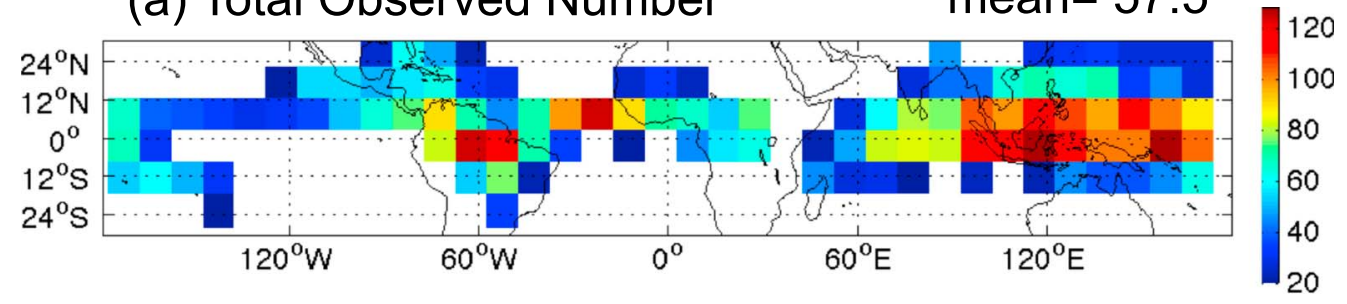

(b) LNB_sounding

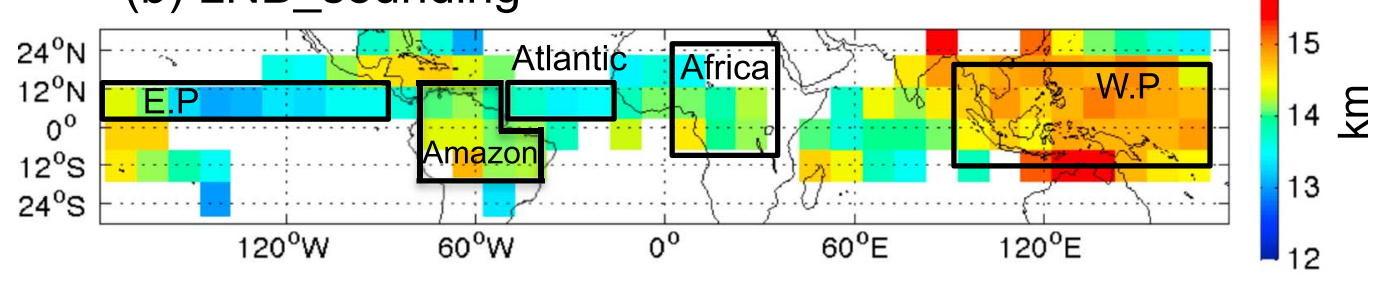

(c) LNB_CTH

\section{mean $=13.28 \mathrm{~km}$}

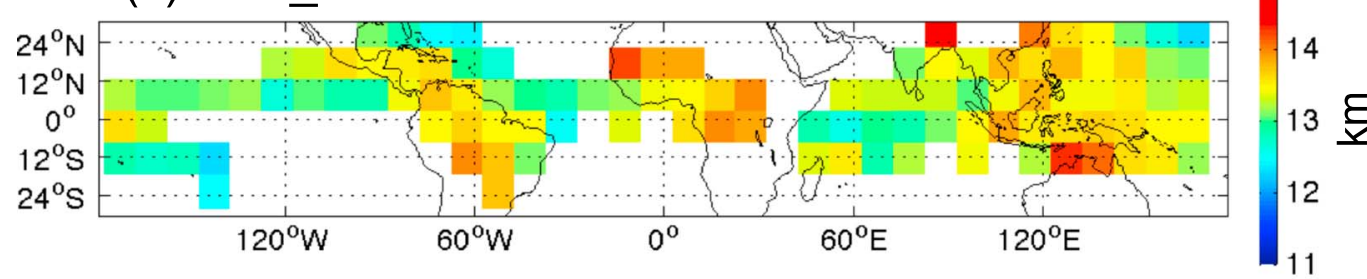

(d) LNB_maxMass

mean $=10.57 \mathrm{~km}$

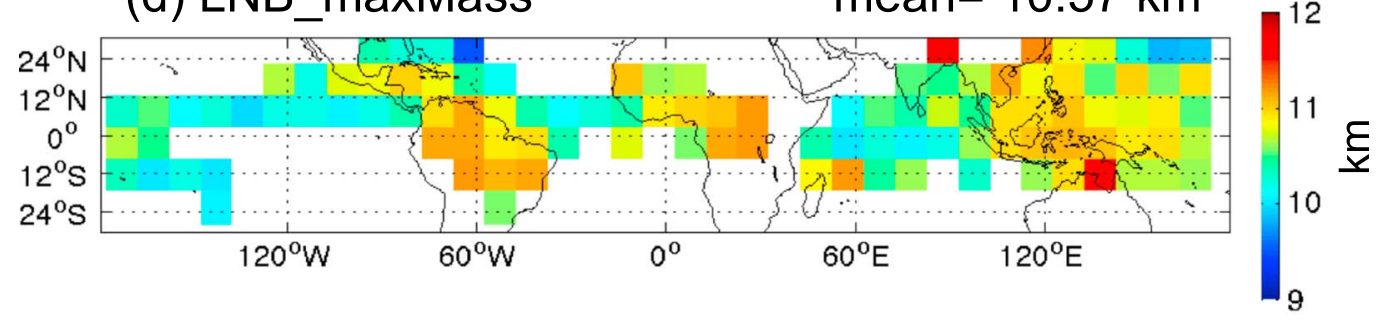

(e) LNB_CBH

mean $=8.37 \mathrm{~km}$



Figure 2. Global distributions of (a) sample size of anvil cloud objects, together with (b) LNB_sounding, (c) LNB_CTH, (d) LNB_maxMass, and (e) LNB_CBH in $10^{\circ} \times 10^{\circ}$ boxes over the whole tropics $\left(30^{\circ} \mathrm{S}-30^{\circ} \mathrm{N}\right)$. Those grid boxes $\left(10^{\circ} \times 10^{\circ}\right)$ with less than 20 anvil cloud objects are left blank.

\section{Regional Variations}

An important finding from the whole-tropics $\left(30^{\circ} \mathrm{S}-30^{\circ} \mathrm{N}\right)$ survey by $T L 12$ is that LNB_observation differs from LNB_sounding in a number of ways: (1) While LNB_sounding is a reasonable upper bound for actual convective development, it has little direct correlation with LNB_observation on a case-by-case basis. (2) The 
(a) LNB_sounding

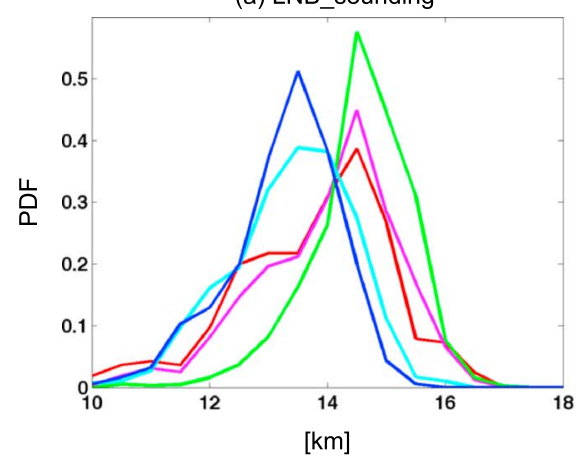

(c) LNB_maxMass

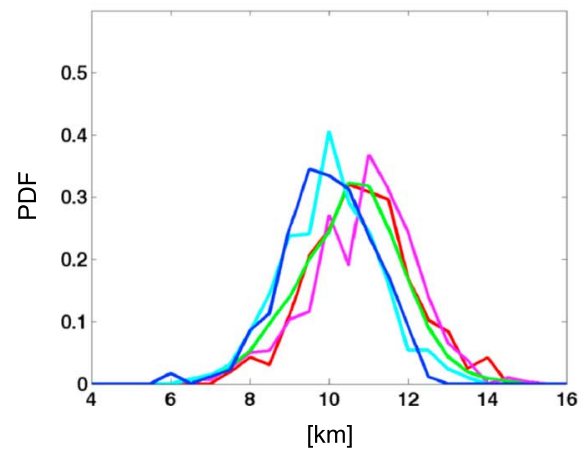

(b) LNB CTH

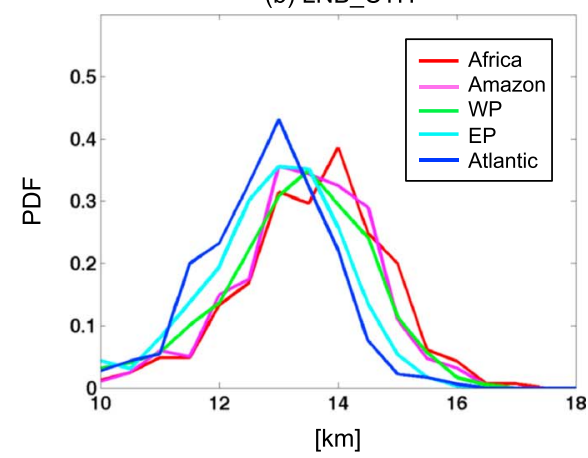

(d) LNB_CBH

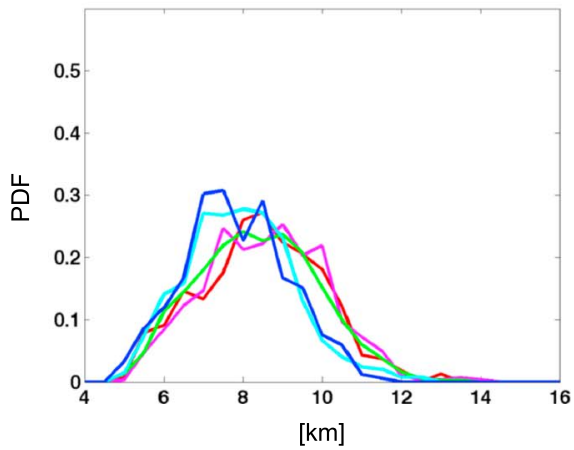

Figure 3. Probability density functions (PDFs) for (a) LNB_sounding, (b) LNB_CTH, (c) LNB_maxMass, and (d) LNB_CBH over different regions.

maximum mass outflow level, LNB_maxMass, is on average more than $3 \mathrm{~km}$ lower than LNB_sounding. (3) If we separate the results based on land and ocean, land deep convection has consistently higher LNB_observation than the ocean convection, although LNB_sounding is similar between ocean and land. In this study, we take one step further to examine the regional variations of LNB_sounding and LNB_observation. With now 5 years of data and a total of 7320 suitable anvil cloud objects, we are able to subset the results based on different regions and ambient environments.

\subsection{Relationship Between Level of Neutral Buoyancy and Deep Convective Outflow}

Figure 2 shows the whole-tropics $\left(30^{\circ} \mathrm{S}-30^{\circ} \mathrm{N}\right)$ distribution of LNB_sounding and LNB_observation. To ensure that enough statistics are collected, grid boxes $\left(10^{\circ} \times 10^{\circ}\right)$ with less than 20 deep convective cloud objects are left blank. To emphasize different convective regimes, we further select five climatologically distinctive regions, namely, tropical Africa $\left(0-35^{\circ} \mathrm{E}, 12^{\circ} \mathrm{S}-24^{\circ} \mathrm{N}\right)$, tropical Amazonia $\left(280-325^{\circ} \mathrm{E}, 15^{\circ} \mathrm{S}-10^{\circ} \mathrm{N}\right)$, the Warm Pool region $\left(90-170^{\circ} \mathrm{E}, 15^{\circ} \mathrm{S}-15^{\circ} \mathrm{N}\right)$, east Pacific Intertropical Convergence Zone (ITCZ, 180-280 $\left.{ }^{\circ} \mathrm{E}, 0-12^{\circ} \mathrm{N}\right)$, and Atlantic ITCZ $\left(310-345^{\circ} \mathrm{E}, 0-12^{\circ} \mathrm{N}\right)$, as marked up in Figure $2 \mathrm{~b}$. Figure 3 shows the corresponding probability density functions (PDFs) for LNB_sounding and three forms of LNB_observation. A few interesting features emerging from Figures 2 and 3 deserve discussion.

LNB_sounding. The rank of LNB_sounding from the highest to the lowest are, respectively, the Warm Pool $(14.9 \mathrm{~km})$, tropical Amazonia $(14.2 \mathrm{~km})$, tropical Africa $(14.5 \mathrm{~km})$, the east Pacific ITCZ $(13.8 \mathrm{~km})$, and the Atlantic ITCZ $(13.7 \mathrm{~km})$. Here we use medians as the representative numbers for comparison (the same as for other comparisons below). These regional differences show that the finding from TL12, namely, LNB_sounding being similar between land and ocean, is actually a result of the cancelation between higher LNB_sounding values over the Warm Pool and lower values over the east Pacific and Atlantic Oceans. It is interesting to note that the two land regions (tropical Africa and tropical Amazonia) have double peaks in the LNB_sounding PDF, one at $14.5 \mathrm{~km}$ and another at $12.5 \mathrm{~km}$, while the three oceanic regions (the Warm Pool, the east Pacific, and the Atlantic ITCZ) have single-peaked PDFs. The double peaks over the two land regions can be largely explained by the diurnal cycle of near-surface temperature over land. Cooler surfaces in early morning lead to lower LNB_sounding, and warmer surfaces in early afternoon cause higher LNB_sounding. 
(a) LNB_sounding - LNB_CTH $(\Delta 1)$



(b) LNB_sounding - LNB_maxMass $(\Delta 2) \quad$ mean $=3.51 \mathrm{~km}$



(c) LNB_sounding - LNB_CBH $(\Delta 3)$

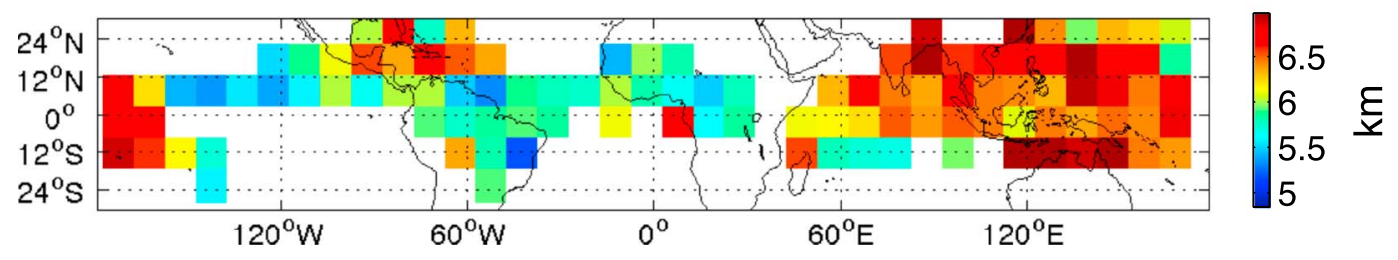

Figure 4. The mean differences of (a) LNB_sounding and LNB_CTH ( $\triangle 1$ in Figure 1), (b) LNB_sounding and LNB_maxMass $\left(\triangle 2\right.$ in Figure 1), and (c) LNB_sounding and LNB_CBH $\left(\triangle 3\right.$ in Figure 1) in $10^{\circ} \times 10^{\circ}$ grid boxes over the whole tropics $\left(30^{\circ}\right.$ $\left.\mathrm{S}-30^{\circ} \mathrm{N}\right)$. Similar to Figure 2 , those grid boxes $\left(10^{\circ} \times 10^{\circ}\right)$ with less than 20 anvil cloud objects are left blank.

LNB_observation. While LNB_sounding sets a rough upper bound for deep convection development, LNB_observation (LNB_CTH, LNB_maxMass, and LNB_CBH) captures actual convective outflow. In terms of LNB_CTH, tropical Africa has the highest value $(13.9 \mathrm{~km})$, followed by Amazonia $(13.7 \mathrm{~km})$ and the Warm Pool $(13.6 \mathrm{~km})$. The east Pacific ITCZ $(13.3 \mathrm{~km})$ and Atlantic ITCZ $(13.1 \mathrm{~km})$ have lower LNB_CTH. It is also of interest to compare LNB_maxMass among the regions because LNB_massMass is most relevant to convective mass transport, as suggested by the ground-based case study by Mullendore et al. [2009]. The highest LNB_maxMass is observed over tropical Africa $(11.1 \mathrm{~km})$ and Amazonia $(11.3 \mathrm{~km})$. The Warm Pool, east Pacific, and Atlantic ITCZ have lower LNB_maxMass (10.9 km, $10.3 \mathrm{~km}$, and $10.3 \mathrm{~km}$, respectively). Therefore, the finding in TL12 that land deep convection has higher LNB_observation than the oceanic counterpart is robust and holds among different regions.

Figure 4 shows the differences between LNB_sounding and three forms of LNB_observation (LNB_CTH, LNB_maxMass, and LNB_CBH). These differences are illustrated as $\Delta Z 1, \Delta Z 2$, and $\Delta Z 3$, respectively, in Figure 1. According to the parcel theory, how much the actual outflow falls short of the LNB set by the ambient sounding can be interpreted as a measure of the magnitude of the entrainment effect: greater entrainment dilution leads to larger difference between LNB_sounding and LNB_observation. Following this interpretation, Figure 4 suggests that deep convective clouds over the Warm Pool tend to be more diluted than those over tropical African and Amazonia. It is noticed that the difference between LNB_sounding and LNB_observation over the east Pacific ITCZ is also small. It is not immediately clear why this is the case. However, we believe that the sample size could be a factor. Our samples of deep convection are far fewer over the east Pacific ITCZ than other regions where convection is prevalent. For example, the number of cases in the $10^{\circ} \times 10^{\circ}$ boxes over the east Pacific ITCZ is only $\sim 28$, compared to $\sim 60$ over the Warm Pool (see Figure 2a). We will revisit this issue when a longer data record with more cases becomes available.

The difference between LNB_sounding and LNB_observation can be cast into a simple framework of a one-dimensional entraining plume model, which can calculate the corresponding bulk entrainment rate 
(a) Entrainment at maxMass

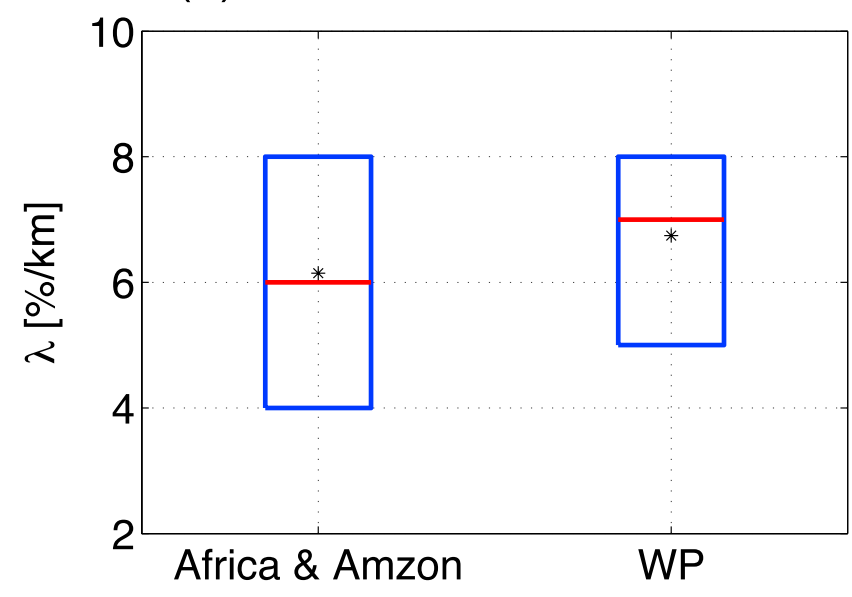

(b)



Figure 5. Box-scatter diagram for (a) the calculated bulk entrainment rates for LNB_maxMass and (b) DCC size over the two tropical land regions (Africa and Amazonia) and Warm Pool. The bottom and top of the blue boxes show, respectively, the $25 \%$ and $75 \%$ percentile. The central lines show the median, and the stars inside the box show the mean.
( $\lambda$; unit: $\% / \mathrm{km})$. Following Luo et al. [2010] and TL12, the entraining plume model is expressed as $\frac{\partial \mathrm{MSE}_{p}}{\partial}=\lambda$ $\left(\partial \mathrm{MSE}_{e}-\partial \mathrm{MSE}_{p}\right)$, where $\mathrm{MSE}=C_{p} T$ $+g z+L_{v} q(T, z$, and $q$ are temperature, height, and specific humidity, respectively; $C_{p}$ is the specific heat of condensation). Subscripts $p$ and $e$ refer to properties of the in-cloud air parcel and of the environment, respectively. $\mathrm{MSE}_{e}$ is estimated from the ambient sounding data, which, in this study, is obtained from the collocated ECMWF analyses. $\mathrm{MSE}_{p}$ is assumed to be equal to $\mathrm{MSE}_{e}$ at the launching level near the surface or $925 \mathrm{hPa}$, whichever has higher MSE (following Liu and Zipser [2005]), and then the equation is integrated from the surface to the corresponding LNB_observation. $\lambda$ is determined iteratively so as to satisfy the condition that the air parcel becomes neutrally buoyant at the height level of LNB_observation.

Figure 5 shows the calculated $\lambda$ for LNB_maxMass for two regions with contrasting convective regimes: the Warm Pool and the two land regions (tropical Africa and Amazonia combined). The east Pacific and Atlantic ITCZ are not included here because of small sample size, but they will be revisited in the future when a larger sample becomes available. We use LNB_maxMass as the representative of LNB_observation in the calculation because it is most directly

connected to convective mass transport. Figure 5 shows that the convective entrainment rates are smaller for the Warm Pool than the two land regions, consistent with the contrast in difference between LNB_sounding and LNB_observation, as shown in Figure 4. Expressing the difference between LNB_sounding and LNB_observation in terms of the bulk entrainment rate makes it more relevant to global modelers who treat convection in cumulus parameterizations that are formulated based on a similar entraining plume model.

Also shown in Figure 5 is the size of the deep convective core (DCC), as defined in section 2. Comparing the DCC size and bulk entrainment rate suggests a negative correlation between the two. The negative relationship has long been assumed in cloud and convection models [e.g., Simpson and Wiggert, 1969; Bacmeister and Stephens, 2011]. The explanation is that larger convective cores are better protected from the environment and thus are less diluted by entrainment (i.e., smaller entrainment rate). Although our results should be treated with caution, they seem to add observational evidence from global satellite observations to support this fundamental assumption.

\subsection{Deep Convective Cores and Internal Vertical Structure}

Despite severe attenuation by heavy precipitation, CloudSat CPR offers a unique view of the internal vertical structure of the convective cores and captures important information on convective intensity, as demonstrated in Luo et al. [2014]. A commonly used method for statistically characterizing radar reflectivity 
(a) Africa \& Amazonia (CC)

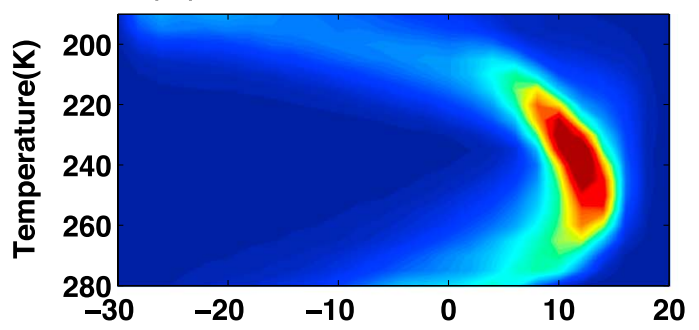

(b) Warm Pool (cc)

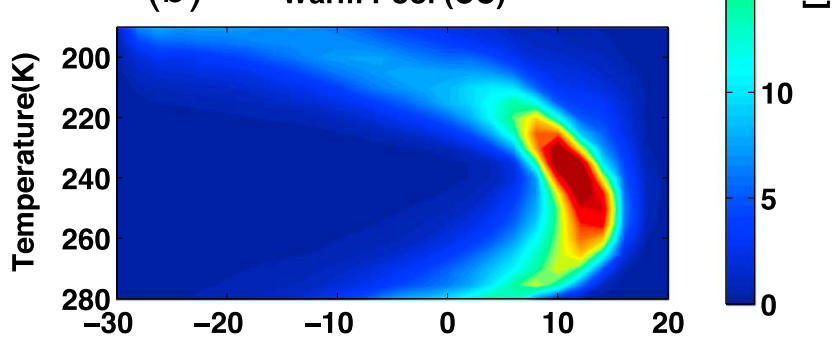

(c) Africa \& Amazonia - Warm Pool (CC)

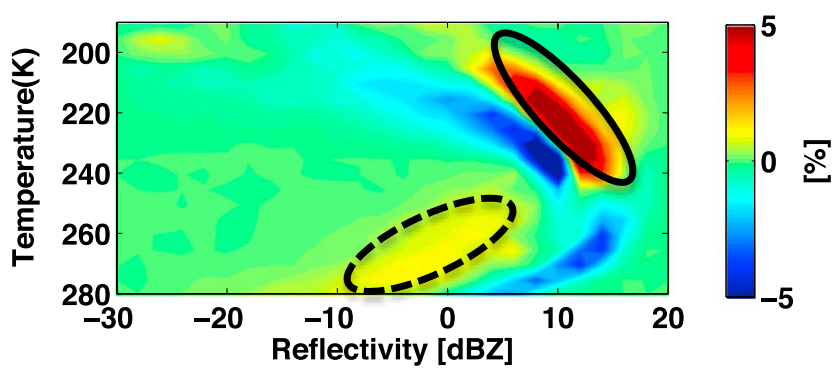

Figure 6. Contoured frequency by temperature diagrams (CFTDs) for deep convective cores (DCCs) over (a) the two tropical land regions (Africa and Amazonia), (b) the Warm Pool, and (c) the difference between them (i.e., Figure $6 a-$ Figure $6 b$ ).

stronger cores that are capable of transporting larger particles to a higher level compared to the oceanic counterparts. Meanwhile, attenuation due to heavy precipitation (i.e., decreasing reflectivities below the melting layer) is also more severe over tropical land than Warm Pool convection (marked as dark dashed ovals), suggesting that land convection produces heavier rainfall. These contrasts in CFTD between land and oceanic deep convective cores are very similar to that between strong and weak convection (sorted by vertical velocity) as reported in Luo et al. [2014]. Hence, CloudSat CPR observations suggest that land convection generates more intense cores than the oceanic counterpart, consistent with direct measurements from cloud-penetrating aircraft [e.g., LeMone and Zipser, 1980; Lucas et al., 1994] and inference made from analyzing TRMM precipitation radar data [Liu and Zipser, 2005; Zipser et al., 2006].

Among the DCCs, we further separate those that overshoot the LNB_CTH from the nonovershooting cores. Figure 7 shows the corresponding CFTDs. By the same criteria as adopted for contrasting land and oceanic cores in Figure 6 (i.e., higher radar echo and more severe attenuation), it is concluded that the overshooting cores are generally more intense than the nonovershooting cores. This is perhaps not a surprise, but it adds confidence to our analysis to see a theoretically sound relationship bear out in satellite observations.

\section{Dependence of Convective Outflow on Cloud System Size and Ambient Humidity}

Finally, we examine how convective outflow is related to midtropospheric relative humidity and size of the convective systems. Midtropospheric relative humidity is known to be a key parameter controlling 




(c) osc - nonosc

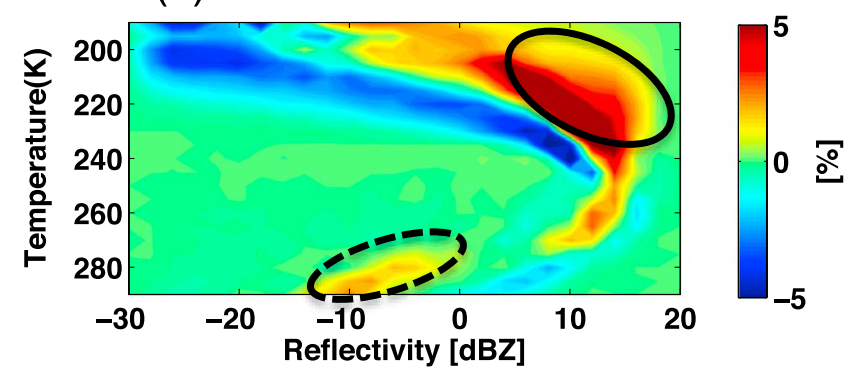

Figure 7. Contoured frequency by temperature diagrams (CFTDs) for (a) overshooting cores (OSC), (b) nonovershooting cores (nonOSC), and (c) the difference between them (i.e., Figure 7a - Figure 7b). convective development [Grandpeix et al., 2004; Jensen and Del Genio, 2006]. We use the relative humidity $(\mathrm{RH})$ averaged between $2.5 \mathrm{~km}$ and $4.5 \mathrm{~km}$ as the midtropospheric $\mathrm{RH}$. Convective system size is related to the vertical extent of convection: larger systems usually grow taller, as shown in previous IR-based surveys [Machado and Rossow, 1993; Rossow and Pearl, 2007]. In this study, $\mathrm{RH}$ is estimated from the collocated ECMWF analyses, and convective system size is defined as the horizontal span of the whole anvil cloud objects as seen by CloudSat CPR. It should be noted that the cloud size investigated in this section refers to the size of the whole convective system and it may behave differently from the embedded DCCs. For example, TL12 found that oceanic deep convection has larger cloud system sizes but the embedded DCCs are smaller, compared to the land counterparts.

Figure 8 shows the average LNB_maxMass as functions of convective system size ( $x$ axis) and midtropospheric $\mathrm{RH}$ ( $y$ axis). LNB_maxMass is chosen to represent LNB_observation partly because its signal is less noisy and partly because this level is most relevant to convective mass outflow and convective transport. We define 80 bins for system size from 10 to $1590 \mathrm{~km}$ with a bin width of $20 \mathrm{~km}$ and 10 bins for midtropospheric RH from 5 to $95 \%$ with a bin width of $10 \%$. To ensure that enough statistics are collected, each bin with sample size less than 20 cases is left blank. The ranges of convective system size plotted in the figure are set to be $50-350 \mathrm{~km}$ over ocean and $50-180 \mathrm{~km}$ over land because land convective systems are usually significantly smaller than their oceanic counterparts. The correlation coefficient between the system size and midtropospheric RH is less than $\sim 0.1$ ( 0.095 for over ocean and 0.068 for over land), so these two variables are largely independent of each other. The directions of LNB gradient (i.e., the increasing trend in LNB) are marked as arrows in the figure.

Figure 8 shows that LNB_maxMass increases with midtropospheric RH but decreases with convective system size, except for larger convective systems (convective system size larger than $250 \mathrm{~km}$ over ocean and that larger than $100 \mathrm{~km}$ over land). The RH dependence of deep convective outflow is consistent with previous findings that a moister midtroposphere reduces the effect of entrainment dilution, which allows convection to develop deeper [Jensen and Del Genio, 2006]. For larger convective systems, the midtropospheric environment is usually very humid (e.g., the sample space is largely empty for size $>150 \mathrm{~km}$ and $\mathrm{RH}<70 \%$ ), which probably explains why there is little RH dependence. The association of higher LNB_maxMass with smaller cloud system size is less straightforward to explain and may appear counterintuitive at first. However, closer examination suggests that one possibility is that variation in convective system size is largely related to convective life stage, which affects the determination of LNB_maxMass. As shown in Futyan and Del Genio [2007], the cloud system reaches the highest cloud top (the minimum cloud top temperature) during the growing stage and the cloud system reaches the maximum size during the mature stage. Therefore, the 


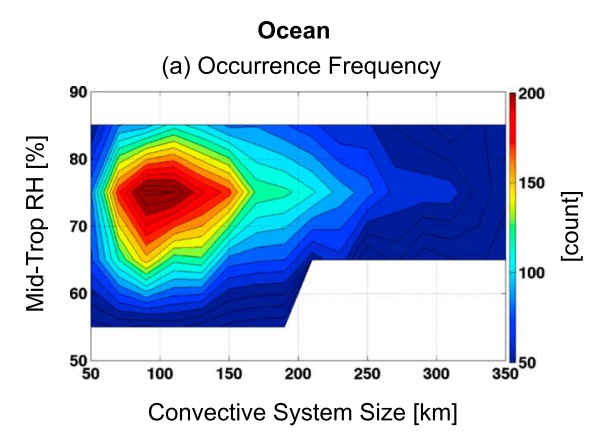

(b) LNB_maxMass

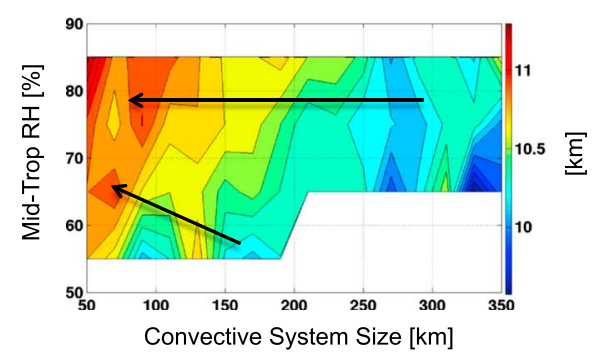

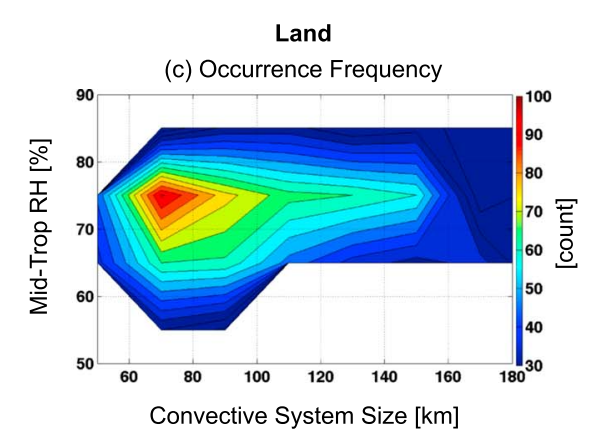

(d) LNB_maxMass

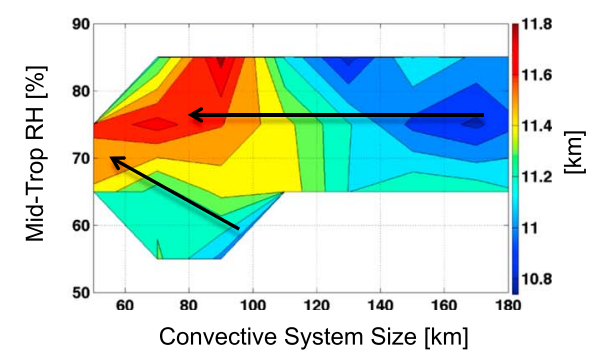

Figure 8. ( $a, c)$ Occurrence frequencies and (b, d) mean LNB_maxMass as functions of convective system size ( $x$ axis) and midtropospheric RH ( $y$ axis) over tropical ocean (Figures $8 \mathrm{a}$ and $8 \mathrm{~b}$ ) and land (Figures $8 \mathrm{c}$ and $8 \mathrm{~d}$ ). Black arrows in the panels $\mathrm{b}$ and $\mathrm{d}$ represent the directions of the gradient of LNB maxMass.

early stages of deep convective systems are likely to be smaller and taller [Takahashi and Luo, 2014]. At this stage, convective updrafts have reached their greatest height and have just started to outflow (the even earlier life stage where the cirrus anvil has not fully developed is not included in this study), leading them to have the highest LNB_maxMass. As the system ages, it grows in size due to continued outflow, but ice particles inside the cirrus anvil (outflow) have already settled to lower altitudes. Consequently, LNB_maxMass as inferred from radar reflectivity profiles will likely have a lower value (compared to a younger outflow). Hence, the result in Figure 8 suggests that characteristics of convective outflow could be a function of convective life stage. An implication is that one should exercise extra care when interpreting snapshots from satellite measurements. Ideally, every satellite snapshot of a deep convective system should carry a tag indicating the corresponding timestamp in the whole convective lifecycle. Takahashi and Luo [2014] made some initial effort to achieve this goal by combining CloudSat and geostationary satellite data. But unfortunately, almost no existing satellite-based cloud products have this feature (with the notable exception of ISCCP) [Vant-Hull et al., 2016], which limits the application in diagnostic analysis.

\section{Summary and Conclusions}

This study is a follow on to an earlier publication by Takahashi and Luo [2012] and aims to provide a more complete characterization of LNB, deep convective outflow, and convective cores of tropical deep convection, and the relationship among them, including regional variations and connection to convective entrainment, internal vertical structure, and dependence on midtropospheric RH and cloud system size. The principal findings are as follows:

1. In terms of regional differences, the Warm Pool has the highest LNB_sounding, whereas tropical Africa has the highest LNB_observation. Both LNB_sounding and LNB_observation are the lowest over the east Pacific and Atlantic ITCZ.

2. The difference between LNB_sounding and LNB_observation can be interpreted as a measure of convective dilution. Using a simple entraining plume model, we show that convection over the Warm Pool has larger entrainment rate (thus convection is more diluted) than the two tropical land regions (Africa and Amazonia). Moreover, the deep convective cores (DCCs) are smaller over the Warm Pool than the two tropical land regions. These results lend observational evidence to a long-standing assumption in convection models concerning the negative correlation between DCC size and entrainment rate. 
3. Comparisons in internal vertical structure of DCCs, including vertical extent of large radar echoes and near-surface attenuation by rain, suggest that the two tropical land regions contain more intense convective cores than the Warm Pool.

4. In general, higher LNB maxMass (defined as level of maximum radar echo inside the fresh anvil) are found to be associated with a moister midtroposphere, because a moister environment reduces the effect of entrainment dilution. The trend is especially pronounced for smaller systems.

5. LNB_maxMass is higher when convective systems are smaller. We postulate that the observed size dependence has to do with convective life stage of our samples. Note that this result does not contradict prior studies based on IR sensors which generally show that large convective systems tend to have colder (higher) cloud tops, because IR-based cloud top and LNB_maxMass are different measures of convective outflow levels. Howerver, LNB_maxMass is probably more representative of convective mass outflow, as suggested by ground-based Doppler radar observations [Mullendore et al., 2009].

In summary, our analysis of CloudSat observations has elucidated a number of important characteristics of tropical deep convection and gained insights into the inner workings of the convective processes. A particularly useful lesson for the global modeling community is the observed relationship among convective intensity, entrainment rate, convective core width, and outflow height. It is a challenge to correctly reproduce these relations in global climate models (GCMs). It is our hope that the observed relationships will contribute to evaluating GCM cumulus parameterization in ways that have not been possible.

Acknowledgments

The research started when the senior author was at CUNY Graduate Center and was completed at the Jet Propulsion Laboratory, California Institute of Technology, under a contract with the National Aeronautics and Space Administration (NASA). The study was partly supported by grant NNN13D455T. The authors would like to thank Jeyavinoth Jeyaratnam of CUNY for computational assistance and W.B. Rossow for insightful discussions. Detailed information on CloudSat data can be found from the CloudSat Data Processing Center at http://cloudsat. cira.colostate.edu.

\section{References}

Bacmeister, J. T., and G. L. Stephens (2011), Spatial statistics of likely convective clouds in CloudSat data, J. Geophys. Res., 116, D04104, doi:10.1029/2010JD014444.

Chung, E. S., B. J. Sohn, and J. Schmetz (2008), CloudSat shedding new light on high-reaching tropical deep convection observed with Meteosat, Geophys. Res. Lett., 35, L02814, doi:10.1029/2007GL032516.

Danielsen, E. F. (1982), A dehydration mechanism for the stratosphere, Geophys. Res. Lett., 9, 605-608, doi:10.1029/GL009i006p00605.

Deng, M., G. Mace, Z. Wang, and E. Berry (2015), CloudSat 2C-ICE product update with a new $Z_{e}$ parameterization in lidar-only region, J. Geophys. Res. Atmos., 120, 12,198-12,208, doi:10.1002/2015JD023600.

Emanuel, K. A. (1994), Atmospheric Convection, pp. 580, Oxford Univ. Press, Oxford, U. K.

Fridlind, A. M., A. S. Ackerman, A. Grandin, F. Dezitter, M. Weber, J. W. Strapp, A. V. Korolev, and C. R. Williams (2015), High ice water content at low radar reflectivity near deep convection-Part 1: Consistency of in situ and remote-sensing observations with stratiform rain column simulations, Atmos. Chem. Phys., 15(20), 11,713-11,728.

Futyan, J. M., and A. D. Del Genio (2007), Deep convective system evolution over Africa and the tropical Atlantic, J. Clim., 20(20), 5041-5060.

Gettelman, A., Salby, M. L., and Sassi, F. (2002), Distribution and influence of convection in the tropical tropopause region, J. Geophys. Res., 107(D10), 4080, doi:10.1029/2001JD001048.

Grandpeix, J. Y., V. Phillips, and R. Tailleux (2004), Improved mixing representation in Emanuel's convection scheme, Q. J. R. Meteorol. Soc., 130(604), 3207-3222.

Hartmann, D. L., and Larson, K. (2002), An important constraint on tropical cloud-climate feedback, Geophys. Res. Lett., 29(20), 1951, doi:10.1029/2002GL015835.

Iwasaki, S., T. Shibata, J. Nakamoto, H. Okamoto, H. Ishimoto, and H. Kubota (2010), Characteristics of deep convection measured by using the A-train constellation, J. Geophys. Res., 115, D06207, doi:10.1029/2009JD013000.

Iwasaki, S., T. Shibata, H. Okamoto, H. Ishimoto, and H. Kubota (2012), Mixtures of stratospheric and overshooting air measured using A-Train sensors, J. Geophys. Res., 117, D12207, doi:10.1029/2011JD017402.

Iwasaki, S., Z. J. Luo, H. Kubota, T. Shibata, H. Okamoto, and H. Ishimoto (2015), Characteristics of cirrus clouds in the tropical lower stratosphere, Atmos. Res., 164, 358-368.

Jensen, M. P., and A. D. Del Genio (2006), Factors limiting convective cloud-top height at the ARM Nauru Island climate research facility, J. Clim., 19(10), 2105-2117.

Kley, D., H. G. Smit, S. Nawrath, Z. Luo, P. Nedelec, and R. H. Johnson (2007), Tropical Atlantic convection as revealed by ozone and relative humidity measurements, J. Geophys. Res., 112, D23109, doi:10.1029/2007JD008599.

Kuang, Z., and C. S. Bretherton (2004), Convective influence on the heat budget of the tropical tropopause layer: A cloud-resolving model study, J. Atmos. Sci., 61, 2919-2927.

LeMone, M. A., and E. J. Zipser (1980), Cumulonimbus vertical velocity events in GATE. Part I: Diameter, intensity and mass flux, J. Atmos. Sci., 37(11), 2444-2457.

Liu, C., and E. J. Zipser (2005), Global distribution of convection penetrating the tropical tropopause, J. Geophys. Res., 110, D23104, doi:10.1029/2005JD006063.

Liu, C., E. J. Zipser, and S. W. Nesbitt (2007), Global distribution of tropical deep convection: Different perspectives from TRMM infrared and radar data, J. Clim., 20(3), 489-503.

Lucas, C., E. J. Zipser, and M. A. Lemone (1994), Vertical velocity in oceanic convection off tropical Australia, J. Atmos. Sci., 51(21), 3183-3193.

Luo, Z., G. Y. Liu, and G. L. Stephens (2008), CloudSat adding new insight into tropical penetrating convection, Geophys. Res. Lett., 35, L19819, doi:10.1029/2008GL035330.

Luo, Z. J., G. Y. Liu, and G. L. Stephens (2010), Use of A-Train data to estimate convective buoyancy and entrainment rate, Geophys. Res. Lett., 37, L09804, doi:10.1029/2010GL042904.

Luo, Z. J., D. Kley, R. H. Johnson, G. Y. Liu, S. Nawrath, and H. G. Smit (2012), Influence of sea surface temperature on humidity and temperature in the outflow of tropical deep convection, J. Clim., 25(4), 1340-1348. 
Luo, Z. J., J. Jeyaratnam, S. Iwasaki, H. Takahashi, and R. Anderson (2014), Convective vertical velocity and cloud internal vertical structure: An A-Train perspective, Geophys. Res. Lett., 41, 723-729, doi:10.1002/2013GL058922.

Machado, L. A. T., and W. B. Rossow (1993), Structural characteristics and radiative properties of tropical cloud clusters, Mon. Weather Rev., 121(12), 3234-3260.

Mullendore, G. L., A. J. Homann, K. Bevers, and C. Schumacher (2009), Radar reflectivity as a proxy for convective mass transport, J. Geophys. Res., 114, D16103, doi:10.1029/2008JD011431.

Riley, E. M., and B. E. Mapes (2009), Unexpected peak near $-15^{\circ} \mathrm{C}$ in CloudSat echo top climatology, Geophys. Res. Lett., 36, L09819, doi:10.1029/2009GL037558.

Rossow, W. B., and C. Pearl (2007), 22-year survey of tropical convection penetrating into the lower stratosphere, Geophys. Res. Lett., 34, L04803, doi:10.1029/2006GL028635.

Sherwood, S. C., T. Horinouchi, and H. A. Zeleznik (2003), Convective impact on temperatures observed near the tropical tropopause, J. Atmos. Sci., 60(15), 1847-1856.

Simpson, J., and V. Wiggert (1969), Models of precipitating cumulus towers, Mon. Weather Rev., 97(7), 471-489.

Stephens, G. L., S. Van Den Heever, and L. Pakula (2008), Radiative-convective feedbacks in idealized states of radiative-convective equilibrium, J. Atmos. Sci., 65(12), 3899-3916.

Takahashi, H., and Z. Luo (2012), Where is the level of neutral buoyancy for deep convection?, Geophys. Res. Lett., 39, L15809, doi:10.1029/ 2012GL052638.

Takahashi, H., and Z. J. Luo (2014), Characterizing tropical overshooting deep convection from joint analysis of CloudSat and geostationary satellite observations, J. Geophys. Res. Atmos., 119, 112-121, doi:10.1002/2013JD020972.

Vant-Hull, B., W. B. Rossow, and C. Pearl (2016), Global comparisons of regional life cycle properties and motion of multiday convective systems: Tropical and midlatitude land and ocean, J. Clim., 29, 5837-5858, doi:10.1175/JCLI-D-15-0698.1.

Wallace, J. M., and P. V. Hobbs (2006), Atmospheric Science: An Introductory Survey, vol. 92, Academic Press.

Wang, C., Z. J. Luo, X. Chen, X. Zeng, W. K. Tao, and X. Huang (2014), A physically based algorithm for non-blackbody correction of cloud-top temperature and application to convection study, J. Appl. Meteorol. Climatol., 53(7), 1844-1857.

Yuan, J., and R. A. Houze Jr. (2010), Global variability of mesoscale convective system anvil structure from A-Train satellite data, J. Clim., 23(21), 5864-5888.

Yuter, S. E., and R. A. Houze Jr. (1995), Three-dimensional kinematic and microphysical evolution of Florida cumulonimbus. Part II: Frequency distributions of vertical velocity, reflectivity, and differential reflectivity, Mon. Weather Rev., 123(7), 1941-1963.

Zipser, E. J., D. J. Cecil, C. Liu, S. W. Nesbitt, and D. P. Yorty (2006), Where are the most intense thunderstorms on Earth?, Bull. Am. Meteorol. Soc., 87(8), 1057. 